\title{
CIUDADANÍA Y BIEN COMÚN EN LA REPÚBLICA ${ }^{1}$
}

\author{
Patricio-Ignacio Carvajal ${ }^{2}$
}

Cuando hablamos de la palabra "república", solemos remontarnos demasiado poco en el tiempo. A lo sumo acudimos al significado que adquirió desde el siglo XVII, según el cual "república" se contrapuso a "monarquía". O saltamos a la actualidad, como en el alemán "Republik", o el francés "république", en que el término se identifica con la organización liberal demócrata del Estado. O, por último, situamos la palabra en el contexto norteamericano; para el cual, lejos de la cuestión monárquica, "republic" se contrapone a antidemocracia. Pero todo esto es superfluo. Lo más aleccionador es reconducir la expresión "república" a su origen latino "Res publica", en el cual literalmente denotamos una "cosa pública", una "cosa común"; en contraposición a la res privata-cosa privada-, en el sentido de que aquellas cosas de titularidad exclusivamente individual.

La idea de Res publica, de "cosa pública", se ha transmitido a otras lenguas. Por ejemplo, en italiano, "il comune"; en alemán, "die Gemeinde"; o, en inglés, "commonwealth". Ahora bien, para el original latino, Res publica -si bien ciertamente podríamos encontrar influjos griegos en su significado-, no hallamos, en cambio, una traducción literal a la lengua de los filósofos. Res publica no es traducible por el adjetivo griego "koinós" (común, público), ni por el sustantivo "lo público": en singular tò koinón, o en plural, tà koiná. En realidad, la correcta traducción griega de Res publica sería "politeia", que es algo así como "buen gobierno de la cosa pública". Así es que debemos familiarizarnos con esta politeia (política). Pero, en mi opinión, no desde las ideas griegas, derivadas desde la noción de polis, sino desde el concepto mucho más provechoso de civitas; por cuanto denota mejor los contenidos esenciales de la Res publica.

1. Michel Bréal ${ }^{3}$ llama la atención sobre el fenómeno de concreción de las palabras originalmente abstractas; es decir, palabras que no mantienen su sentido abstracto inicial, referido a una acción, a una cualidad o a una condición, sino que terminan por referirse a un objeto material. El sufijo latino "-tas" juega un papel fundamental en la formación de aquellas palabras abstractas que indican una cualidad o una condición -como en dignitas, dignidad, cupiditas, deseo, imbecillitas, imbecilidad, etc.-. Este sufijo corresponde al griego "-tes" - dikaiótes, justicia, filótes, amistad, etc.-. Ahora bien, en algunos términos latinos esta función del sufijo "-tas" tiende a perderse. Así en "civitas", que designa algo tan concreto como "ciudad". Pero -este es el punto central- lo cierto es que originalmente significaba la cualidad propia

1 El texto corresponde a un discurso pronunciado con ocasión de la clausura del Bachillerato en Servicio Público organizado por la Fundación Jaime Guzmán, el año 2012. El autor agradece la invitación realizada en atención a su perspectiva académica. Dada la naturaleza oral de esta intervención, solo se ofrecen unas pocas citas bibliográficas básicas

2 Doctor en Derecho. Correo electrónico: carvajal@ uc.cl.

3 BréAL, Michel (1897): Essai de sémantique (Sciencie des significations) (París, Librairie Hachette) pp. 149 y 150. 
del ciudadano (civis). En suma, si bien la palabra civitas -a diferencia de dignitas o cupiditas- denota un espacio concreto, este no es su sentido abstracto original, sino uno derivado: el significado primario se refería -como ha quedado dicho- a una cualidad o condición del ciudadano. Y de hecho, por tanto, solo esta acepción derivativa y material de civitas puede valer como sinónimo de los términos griegos polis (ciudad) y hasta de politeia (política). La derivación de la palabra civitas (ciudad) desde civis (ciudadano), fue retomada más tarde por Émile Benveniste ${ }^{4}$. Se debe recordar que una regla básica de la filología es que las palabras más breves son el origen de aquellas más largas. Así, de civis proviene "civi-tas". Es decir, el ciudadano es el origen y el sustento de la ciudad. Los ciudadanos dan lugar a la ciudad. No a la inversa. Bajo esta perspectiva, en realidad sería un error traducir civis como ciudadano. Más bien, civis se debe traducir como "conciudadano", puesto que al decirse simplemente "ciudadano", se reduce su significado a la condición de un individuo solo, y no al conjunto de personas que constituye políticamente la ciudad. Como dijo el entrañable y recordado colega Giuliano Crifo ${ }^{5}$, civis no es un término absoluto, sino relativo: no soy un civis por mí y ante mí, sino que solo soy civis respecto de otro que también es civis.

Todo esto es mucho más que solo un juego lingüístico. En la cultura romana, especialmente en la época republicana, se entendía sustancialmente que el ciudadano daba lugar a la ciudad, no la ciudad al ciu-

\footnotetext{
4 Benveniste, Émile (1970): Deux modèles linguistiques de la cité (Mélanges Lévy-Strauss, 1) pp. 589-596.

5 Crifò, Giuliano (20044): Civis. La cittadinanza tra antico e moderno (Roma, Laterza) passim, esp. pp. 26 y 27.
}

dadano; y por esta primacía esencial, a nadie se le habría ocurrido, por ejemplo, que la ciudad cobrara impuestos a los ciudadanos, o que la autoridad política (es decir, la autoridad ciudadana) estuviera legitimada para ejercer la fuerza sobre un ciudadano. Era imposible que la ciudad actuara contra un ciudadano, simplemente porque, sin cada uno de ellos, esta no podía existir.

En Grecia, en cambio, la situación era radicalmente opuesta. Así como del latín civis se construye "civi-tas", en griego, desde polis (ciudad) proviene el término más largo "poli-tés" (ciudadano). En Grecia la ciudad era el fundamento de la cualidad de ciudadano; de modo que aquí sí cabían los impuestos, y toda otra clase de cargas correlativas a la cualidad de ciudadano que brindaba la ciudad. Un hombre era ciudadano solo gracias a que la ciudad se lo permitía: sin ciudad, no hay ciudadanos. Esta concepción está clara en Aristóteles, Politica 1.2.1253a: “... Y por la naturaleza, el Estado es anterior a la familia y a cada uno de nosotros, porque el todo debe ser necesariamente anterior a la parte...". Como se ve, en el pensamiento griego, de la polis proviene el polités y hasta su familia. Esto contrasta claramente con Cicerón, De re publica 6.13.13, quien define los grupos políticos como: "concilia coetusque hominum iure sociati, quae civitates appellantur" ("concilios y reuniones de hombres asociados en derecho, los cuales se llaman ciudades"). De esto hablamos cuando decimos que la "ciudad" u, hoy, el "Estado", están al servicio de la persona, y no a la inversa.

\section{Propongo contrastar todo esto} con nuestra realidad, a la luz del artículo $1^{\circ}$ inciso cuarto de nuestra Constitución, que señala: "El Estado está al servicio de la persona humana y su finalidad es promover el bien 
común, para lo cual debe contribuir a crear las condiciones sociales que permitan a todos $y$ a cada uno de los integrantes de la comunidad nacional su mayor realización espiritual y material posible...”.

Se debe ser cuidadoso al analizar el texto constitucional. Ante todo, resalta el lugar central que le cabe a la "persona humana". De hecho, su dignidad y libertad -ya previamente protegidas en el primer inciso del mismo artículo- aparecen como el punto de anclaje de toda la regulación constitucional. Así es que nuestra sociedad política se establece iure, como decía Cicerón, pero sobre la base de la dignidad y de la libertad humanas; las cuales constituyen elementos prejurídicos, y por tanto de mucha mayor entidad que el Derecho mismo. Vale decir: de civis, "civi-tas". No aparece aquí la voluntad ni menos la sola utilidad del hombre como presupuestos de nuestra asociación. Así es que nuestra conformación iure no es un contrato metafísico, como creía Rousseau; o un acuerdo funcional, como pensaba Rawls. Más bien, todo lo dicho, más otros antecedentes que aquí me economizo, dan como resultado lo que en el siglo XIX ya planteaba Antonio Rosmini ${ }^{6}$, respecto de que no hay "en el gobierno social algún poder legitimo para impedir a los individuos que componen la sociedad la consecución del verdadero bien humano... [de lo cual] se sigue que los hombres al asociarse no enajenan, ni han jamás enajenado, ni pueden enajenar, su derecho a tender hacia tal fin; y que sería del todo absurdo pensar que estos habrian puesto voluntariamente a merced de algún gobierno la propia perfec-

\footnotetext{
6 Rosmini, Antonio (1858², pero 1839): La società e il suo fine, en Filosofia della Politica, vol. I, Opere Edite ed Inedite dell'Abate Antonio Rosmini-Serbati roveretano, vol. XX (Milán, Tipografia e Libreria Arcivescovile ditta Boniardi-Pogliani di E. Besozzi) p. 152.
}

ción y la propia felicidad: ya que es moral y físicamente imposible que el hombre renuncie a su recompensa final, y cesaría toda razón de someterse a un gobierno cuando este no tuviese por único su oficio de defender el derecho que tiene cada uno desde su propia naturaleza a la propia felicidad, y de procurarles los medios".

Por otra parte, volviendo al artículo $1^{\circ}$ inciso cuarto de la Constitución, llama la atención la frase "el Estado está al servicio de la persona humana”. Esto, dicho así, sin más, resulta una cosa absurda. No existe un "Estado servicial" directamente con cada individuo, aunque así lo malentienda mucha gente que vocifera en las calles. Por un lado, los bienes particulares de cada uno son, en su sentido más profundo, intransferibles; $y$, por otro, el "Estado del bienestar", o "social”, es otra cosa. Es inimaginable un Estado sirviéndonos a cada uno de nosotros en nuestras múltiples y particulares necesidades -y más inimaginable aún que servirnos, sería que el Estado efectivamente nos satisficiere-. En realidad, la frase quiere decir otra cosa: entre el modelo de ciudad romana y de ciudad griega, se ha preferido la romana; por tanto, los cives, la sociedad política, damos existencia al Estado, somos anteriores a él; a la inversa de lo que opinaba Aristóteles. Sin cives no hay civitas; sin ciudadanos, no hay Estado -esta es la primacía de la persona a la que ya me referí-. En realidad, el texto constitucional es indivisible; vale decir, no se comprende si solo se cita parcialmente. El Estado sirve a la persona humana, le es útil, en cuanto contribuye a crear condiciones sociales que permitan a todos y cada uno su mayor realización espiritual y material posible. El Estado sirve a la persona a través de la promoción del "bien común”. Por tanto, el Estado sirve directamente a la Res publica. 
3. La verdad, yo no les puedo decir qué cosa sea, hoy, el bien común. Pero al menos puedo hacer dos prevenciones sobre aquello que no es, en atención a la engañosa lección del artículo $1^{\circ}$ que refiere el bien común "a todos y a cada uno".

La primera prevención sobre aquello que no es el bien común, es esta. El bien común no es el bien público, no es solo el bien de "todos". Es decir, el bien común no se debe confundir con el bien del cuerpo social entendido como organización. Así lo señalaba también Rosmini, ahora en su Filosofia: "Se debe distinguir el bien común del bien público: cosas que se confunden entre si con gran daño para la ciencia del derecho público, y de la humanidad, impedida, con tales confusiones de conceptos, de encontrar aquella constitución social que le conviene, y que va buscando en vano. / El bien común es el bien de todos los individuos que componen el cuerpo social, y que son sujetos de derechos; el bien público, por el contrario, es el bien del cuerpo social considerado en su totalidad, o bien considerado, según la manera de ver de algunos, en su organización. / El principio del bien público, sustituyendo aquél del bien común, es la utilidad sustituyendo la justicia; es la Política que, tomando entre sus manos prepotentes al Derecho, permite hacer a aquel gobierno lo que más le plazca"7.

Cuando hablamos, por ejemplo, de la expropiación por causa de utilidad públi$c a$, tampoco estamos girando hacia lo que aquí se llama bien público. Ante todo, la utilidad pública contemplada para la expropiación no mira necesariamente a toda la organización política. Así ya estaba claro en

\footnotetext{
7 Rosmini, Antonio (1846, pero $1845^{2}$ ): Filosofia del Diritto, vol. II, en Filosofia della Morale e del Diritto, vol. VI, Opere Edite ed Inedite dell'Abate Antonio Rosmini-Serbati prete roveretano, vol. XX (Milán, Intra Tipografia di Paolo Bertolotti) p. 547.
}

1872, en un informe relativo a la expropiación de terrenos para la construcción de la Avenida del Ejército Libertador, en Santiago, emitido por los señores Jerónimo Urmeneta, Domingo Arteaga Alemparte, Manuel Valdés Vigil y Tadeo Reyes: "La utilidad del Estado ¡se encuentra solamente en aquello que aprovecha a toda la comunidad nacional... de un modo directo e inmediato? En tal caso, podría asegurarse que ninguna, o casi ninguna, de las expropiaciones autorizadas por nuestros diversos congresos ha sido constitucional' ${ }^{\text {. }} \mathrm{La}$ diferencia entre bien común y bien público es cualitativa, como aquí se ve -el bien común no necesariamente coincide con el de toda la organización política-. Por otra parte, ciertamente se evita avasallar los bienes individuales en nombre de la consecución del bien común. El caso de la expropiación es muy ilustrativo también a este respecto: como se sabe, esta debe contemplar una justa indemnización al expropiado. Nótese que el expropiado podría incluso beneficiarse económicamente de una obra realizada en virtud del bien común -v. gr. si la parte restante de un predio, que queda en manos del particular, obtiene plusvalía por las obras públicas en la parte expropiada-; pero dicha ventaja individual no debe ser tomada en cuenta para efectos de su indemnización de perjuicios. Esto revela que es errada la tendencia a simplificar en clave económica el bien común y el bien particular; pues, si ello fuera correcto, ese eventual beneficio económico del expropiado sí tendría que descontarse de su indemnización. La sutileza del bien común revela claramente su carácter exorbitante de las solas consideraciones económicas. Es, en efecto, un dominio de "lo político", con todos sus delicados

\footnotetext{
8 Huneeus, Jorge (1879): La constitución ante el congreso, 1 (Santiago, Imprenta de los Tiempos) p. 56.
} 
equilibrios prudenciales; que solo en algunas ocasiones podría entrar en contacto con los bienes económicos particulares. $\mathrm{Y}$ de aquí que sea muy esclarecedor que nuestro texto constitucional enlace el "bien común" con las "condiciones sociales".

La segunda prevención sobre aquello que no es el bien común, es esta. No podemos confundir el bien común con la sumatoria de los bienes privados de los ciudadanos. Es decir, se debe tener cuidado con confundir el bien común con el que se da "a cado uno". Pues una Res publica, así entendida, no pasa de ser simplemente una agregación de res privatae. Hay también una diferencia cualitativa entre bien común y suma de bienes particulares. Este es el error, por ejemplo, de Friedrich Hayek, Premio Nobel de economía en 1974, cuando en su obra de 1988 "The fatal conceit. The errors of socialism" ("La fatal arrogancia. Los errores del socialismo"), dice: "Uno de los peores abusos del término 'social', que aniquila totalmente el significado del sustantivo a que se aplica, es el casi universal empleo de la expresión 'justicia social'... Suele afirmarse que el calificativo 'social' es aplicable a todo aquello que reduce o elimina las diferencias de renta... Y así, el uso del término 'social' se hace virtualmente equivalente a promoción de la 'justicia distributiva'. Ahora bien, todo ello es radicalmente incompatible con un orden de mercado competitivo y con el aumento $e$ incluso el mantenimiento de la población y la riqueza actuales. De este modo, por medio de tales errores, se llega a llamar 'social' lo que en realidad constituye el principal obstáculo para la buena marcha de la 'sociedad'. Lo 'social' debería más bien tacharse de antisocial"”.

9 HaYeK, Friedrich (1988): The fatal conceit. The errors of socialism, en The Collected Works of Friedrich August Hayek, vol. I (Londres, Routledge) p. 118.
Este pensamiento - una versión acrítica del capitalismo- es capaz de excluir la propia justicia distributiva del horizonte político; pues, claro, la sutileza cualitativa entre bien común y bienes individuales resulta invisible para los modelos económicos.

4. Nada de esto puede estar más lejos del principio de subsidiariedad establecido en el inciso tercero del mismo artículo $1^{\circ}$ de la Constitución; pero, por sobre todo, promovido por la Iglesia ya desde la encíclica Rerum novarum, de 1891, en adelante. En el principio de subsidiariedad se articulan, por supuesto, tanto la justicia conmutativa como la distributiva; a la par que se impone a los Estados el deber de intervenir cuando los particulares no sean capaces de obtener el bien común -incapacidad que no solo es pragmática, sino también ideal-. Otra cosa son nuestras las visicitudes de nuestra propia historia política, por las cuales el liberalismo económico en apariencia se conjugó con el principio constitucional de subsidiariedad -mas, exclusiva y pragmáticamente en su aspecto contrario: no intervenir en las actividades desarrolladas adecuadamente por los particulares-. Ese contubernio, tan circunstancial, hoy se paga muy caro. Se denosta por la prensa al Estado subsidiario, como si fuera sinónimo de Estado ultraliberal. Lo cual pone en riesgo el orden social propuesto por la Iglesia -cuya introducción en nuestra Constitución es sabidamente un mérito de Jaime Guzmán-, y que a mi juicio vale en cuanto aparece como el más justo y humano. Como sea, por la vía de la suma de los bienes particulares volvemos a caer, paradójicamente, en la confusión entre bien común y bien público: la utilidad de la mayoría determina de manera aplastante el destino de la minoría. Teniendo a la vista nuestro contexto 
histórico y político podríamos parafrasear a Rosmini así: "El principio del bien público, sustituyendo aquél del bien común, es la utilidad sustituyendo la justicia; es la [Economía] que, tomando entre sus manos prepotentes al Derecho, permite hacer a aquel gobierno lo que más le plazca".

Ahora bien, cuando señalo que el capitalismo confunde el bien común tanto con el bien público como con una suma de los bienes privados, no estoy trazando una opinión marxista. Para Marx, la pobreza de los trabajadores en el capitalismo solo podía extenderse e intensificarse; y por ello el capitalismo no podía ser reformado sino que requería ser destruido. En fin, para él, el capitalismo no permitía jamás que los trabajadores participaran de la riqueza generada. Esto ya fue certeramente cuestionado por Karl Popper. Y nuestra propia historia reciente también lo desmiente. Aunque esté lejos de terminar la lucha contra la pobreza, esta ha disminuido ostensiblemente en los últimos años. Así es que el desarrollo del mercado ha sido, sin duda, un efectivo método de desarrollo que debemos apreciar y conservar. Pero el problema es otro, por cuanto la economía, por sí sola, no puede colmar en su totalidad el ámbito de "lo político"; las "condiciones sociales", según la Constitución; lo cual yo he llamado la Res publica. Precisamente, el problema tanto del marxismo como del capitalismo es que ambas son posiciones esencialmente materialistas; y, por tanto, en ambas posiciones olvidan que el bien común tiene por norte generar condiciones sociales que permitan la "mayor realización espiritual y material posible". Esta, la "realización espiritual', es una de las cuestiones más descuidadas, hoy.

No me voy a referir aquí a la dimensión religiosa de las personas que componen la sociedad civil como "lo espiritual" -pues esta es una cuestión demasiado gruesa como para ponerse en duda-. Ahora me refiero a una cuestión mucho más cotidiana y urgente. Vivimos a tal punto el materialismo -ese que nos hace proscribir hasta la justicia distributiva y, con ello, el núcleo mismo de la subsidiariedad-, que la realización espiritual se ha confundido con la material. Si tenemos, somos felices. Somos felices porque tenemos. Hemos disuelto la tensión entre cantidad y cualidad; como si bastara que el Estado busque "la mayor realización... material posible”, sin más. Esta degradación propiamente "espiritual" se observa por todas partes. Una de sus vertientes consiste en que las personas no valgan como tales, sino que por su número. Así, historiadores como Gabriel Salazar -si no me equivoco, según le escuché en una conferencia para los estudiantes de Derecho de mi Facultad-, proponen la legitimidad política como la "legitimidad de la calle”. Entonces, lo que vale es el número de personas en la calle; no las personas mismas. Y, por el otro costado, se sostiene que las personas valen como números de una encuesta. Que los encuestadores sean los verdaderos "gurú" de la política actual, es una situación que solo se puede lamentar $-\mathrm{y}$ no se prevé que esto cambie, a pesar de sus gruesos errores en la última votación municipal-. Hoy, los problemas sociales y hasta los liderazgos políticos se resuelven por encuestas. Se ha confundido los instrumentos con los fines; los bienes públicos y los bienes privados con el bien común; la ciudad con los ciudadanos. Y de paso, se ha "cosificado" hasta el extremo a las personas.

Por ejemplo, se insiste en fórmulas económicas para solucionar las demandas estudiantiles: préstamos en condiciones que, según se propone, realmente pueden considerarse adecuadas. Pero ello no resulta. El problema "social" no se resuelve. Los técnicos observan atónitos e impotentes este fracaso. $\mathrm{E}$ insisten una y otra vez en sus explicaciones, 
como si la gente no supiera de sobra qué es una tasa de interés conveniente. Como sea, el resultado político concreto es que hay varios miles de personas protestando en las calles... $\mathrm{Y}$ es que la cuestión, en realidad, es mucho más profunda y "espiritual": las personas no están contentas, "socialmente" contentas -por cierto, las encuestas dicen que sí lo están-. Hacer oídos sordos a ello es no comprender que el bien común también debe promover el bien espiritual. Esa es la política en su sentido más profundo. Las soluciones pasan más por la identificación con un mensaje que por unas sumas y unas restas.

Ojalá que Uds., que han demostrado un interés y una capacidad especiales para la Res publica - uno de los asuntos más serios y trascedentes en la actividad humana-, no olviden nunca que ser civis, "conciudadano", es una cualidad que se tiene respecto de los otros y que empapa a la persona toda, tanto en sus aspectos materiales como espirituales. 